\title{
Komponen Peragam dan Ragam Genetik Paternal pada Sifat Pertumbuhan Sapi Aceh
}

\section{Genetic Paternal Covariance and Variance Components for Growth Traits in Aceh Cattle}

\author{
W.P.B. Putra, Sumadi, dan T. Hartatik \\ Fakultas Peternakan, Universitas Gadjah Mada Yogyakarta \\ Jl. Fauna No. 3 Bulaksumur, Yogyakarta, 55281 \\ e-mail: banchet_putra18@yahoo.co.id \\ (Diterima : 28 November 2013 ; Disetujui : 18 Februari 2014)
}

\begin{abstract}
ABSTRAK
Penelitian ini bertujuan untuk mengetahui (pe)ragam genetik paternal sifat pertumbuhan pada sapi Aceh. Sifat pertumbuhan terdiri atas berat lahir (BL), berat sapih (BS), berat setahunan/yearling (BY), berat akhir (BA), pertambahan berat badan harian (PBBH) dan weight/age (W/A). Komponen covariansi dan variansi yang diperoleh digunakan untuk mengestimasi heritabilitas $\left(h^{2}\right)$ dan korelasi genetik $\left(r_{G}\right)$. Penelitian ini dilakukan di Balai Pembibitan Ternak Unggul (BPTU) - Hijauan Pakan Ternak (HPT) Sapi Aceh Indrapuri dari bulan Maret sampai April tahun 2013. Materi penelitian ini berupa data catatan sifat produksi ternak dari tahun 2010 sampai tahun 2012. Hasil penelitian menunjukkan bahwa standard error (SE) heritabilitas terendah pada $\mathrm{BL}(0,15 \pm 0,13)$. Sebagian besar nilai korelasi genetik pada sifat pertumbuhan termasuk kategori positif dan tinggi $(\geq 0,50)$. Nilai SE terendah pada korelasi genetik terdapat pada korelasi antara BL dan PBBH prasapih $(0,55 \pm 0,54)$, BL dan $\mathrm{PBBH}$ pascasapih $(0,63 \pm 0,62), \mathrm{PBBH}$ prasapih dan $\mathrm{PBBH}$ pascasapih $(0,71 \pm 0,33), \mathrm{PBBH}$ pascasapih dan W/A $(0,72 \pm 0,33)$ dan BA dan W/A $(0,94 \pm 0,69)$. Disimpulkan bahwa seleksi berdasarkan sifat pertumbuhan dapat menyebabkan performans sapi Aceh meningkat.
\end{abstract}

Kata kunci : sapi Aceh, sifat pertumbuhan, heritabilitas, korelasi genetik

\section{ABSTRACT}

This research was conducted to investigate paternal genetic covariance and variance for growth traits in Aceh cattle. Growth traits noticed consist of birth weight $(B W)$, weaning weight $(W W)$, yearling weight $(Y W)$, final weight $(F W)$, Average Daily Gain $(A D G)$ and Weight/Age (W/A). Covariance and variance results were used for estimate heritability $\left(h^{2}\right)$ and genetic correlation $\left(r_{G}\right)$. The research was done at Indrapuri's Breeding and Forages Centre (IBFC) of Aceh cattle from March 2013 to April 2013. The materials of this research consisted of growth records from 2010 to 2012. The results indicated that the lowest standard error (SE) value of heritability was on $B W(0.15 \pm 0.13)$. Most of genetic correlation was on growth traits was positive and high category $(\geq 0.50)$. The lowest $S E$ value was found in correlation between $B W$ and preweaning $A D G(0.55 \pm 0.54), B W$ and post-weaning $A D G(0.63 \pm 0.62)$, pre-weaning $A D G$ and postweaning $A D G(0 . \overline{7} \pm 0.33)$, post-weaning $A D G$ and $W / A(0.72 \pm 0.33)$ and $F W$ and W/A (0.94+0.69). It could be concluded that most of genetic correlation value on Aceh cattle's growth traits were positive and high, therefore the selection based on growth traits caused increasing performance in the Aceh cattle.

Keywords: Aceh cattle, growth traits, heritability, genetic correlation

\section{PENDAHULUAN}

Sapi Aceh ditetapkan sebagai rumpun sapi asli Indonesia pada tahun 2011 oleh
Menteri Pertanian Republik Indonesia melalui Keputusan Menteri Pertanian Nomor: 2907/Kpts/OT.140/6/2011 (Jamaliah, 2010). Sapi Aceh memiliki kemampuan cepat 
beradaptasi pada berbagai jenis pakan lokal antara lain dedaunan, rumput dan leguminosa baik dalam keadaan segar maupun kering (Umartha, 2005). Produktivitas ternak dipengaruhi oleh faktor genetik (internal) dan faktor lingkungan (eksternal) dan juga interaksi kedua faktor tersebut. Faktor eksternal bersifat temporer (berubah-ubah) dari waktu ke waktu, dan tidak diwariskan kepada keturunannya. Faktor internal bersifat baka, tidak akan berubah selama hidupnya sepanjang tidak terjadi mutasi dari gen penyusunnya dan dapat diwariskan kepada keturunannya. Kedua hal inilah yang menyebabkan produktivitas ternak berbeda dari suatu lokasi dengan lokasi lainnya.

Untuk meningkatkan produktivitas ternak dapat dilakukan dengan melakukan seleksi berdasarkan bobot badan. Seleksi merupakan salah satu cara untuk meningkatkan performans disamping manajemen pemeliharaan. Beberapa hal seperti sifat individu, silsilah dan kemampuan reproduksi perlu diperhatikan dalam seleksi ternak. Sifatsifat pertumbuhan yang dapat ditingkatkan performansnya antara lain berat lahir, berat setahunan, PBBH prasapih dan $\mathrm{PBBH}$ pascasapih (Kurnianto, 2009). Untuk menghitung besarnya proporsi dari keragaman suatu sifat anak keturunannya maka perlu dihitung angka pewarisan sifat atau heritabilitas $\left(h^{2}\right)$. Jika angka pewarisan pada suatu sifat tinggi maka diharapkan keunggulan tetua yang diwariskan kepada keturunannya juga tinggi.

Seleksi pada bobot badan dapat dilakukan sedini mungkin agar efisien. Penentuan sifat yang diseleksi dapat dilakukan bila telah diketahui besarnya nilai korelasi genetik antar sifat-sifat pertumbuhan. Korelasi genetik dapat terjadi karena ekspresi dua sifat atau lebih yang disebabkan oleh gen yang sama, yaitu gen pleiotropik dimana gen tersebut akan berekspresi pada waktu yang berbeda. Estmasi nilai heritabilitas dan korelasi genetik belum pernah dilakukan di BPTU-HPT Sapi Aceh Indrapuri sehingga perlu dilakukan penelitian untuk mengetahui nilai heritabilitas dan korelasi genetik pada sifat-sifat pertumbuhan yang berguna sebagai dasar seleksi ternak.

\section{METODE}

\section{Pengumpulan Data}

Penelitian ini dilakukan di Balai Pembibitan Ternak Unggul (BPTU) - Hijauan Pakan Ternak (HPT) Sapi Aceh Indrapuri pada bulan Maret 2013 sampai April 2013. Materi dalam penelitian ini menggunakan data catatan ternak meliputi berat lahir, berat sapih (205 hari), berat setahun (365 hari), berat akhir (550 hari), tanggal lahir dan silsilah ternak dari tahun 2010 sampai 2012. Jumlah Data recording ternak yang digunakan untuk estimasi heritabilitas dan korelasi genetik tersaji pada Tabel 1 dan Tabel 2.

\section{Koreksi Data}

Data berat lahir dan berat sapih dikoreksi terhadap jenis kelamin dan umur induk. Berat sapih, berat setahun dan berat akhir masing-masing dikoreksi terhadap umur 205 hari, 365 hari dan 550 hari. Tenggang waktu dihitung sesuai petunjuk Hardjosubroto (1994) yaitu menghitung selisih waktu antara pada saat ternak ditimbang dengan waktu saat penimbangan sebelumnya dan dihitung menggunakan kalender Julian date (Gambar 1). Rumus yang digunakan untuk memperoleh berat badan terkoreksi dilakukan menurut petunjuk Riady (2007) sebagai berikut:

$\mathrm{BL}_{\mathrm{T}}=\mathrm{BL} \times$ FKJK $\times$ FKUI

$$
F K J K_{\text {betina }}=\frac{\bar{X} B L \quad \text { jan tan }}{\bar{X} B L \quad \text { betina }}
$$

$$
\begin{aligned}
& B S_{T}=\left(\frac{B S-B L}{\text { umur }} \times 205+B L\right) \times(F K U I) \times(F K J K) \\
& \mathrm{BY}_{\mathrm{T}}=\left(\frac{\mathrm{BY}-\mathrm{BS}}{\text { tenggang waktu }} \times 160+\mathrm{BS}_{\mathrm{T}}\right)(\mathrm{FKJK}) \\
& \mathrm{BA}_{\mathrm{T}}=\left(\frac{\mathrm{BA}-\mathrm{BS}}{\text { tenggang waktu }} \times 345+\mathrm{BS}_{\mathrm{T}}\right)(\mathrm{FKJK}) \\
& \mathrm{PBBH} \text { prasapih }=\frac{B S-B L}{\text { tenggang waktu }} \times(F K J K)
\end{aligned}
$$

$\mathrm{PBBH}$ pascasapih $=\frac{B B-B S}{\text { tenggang } \text { waktu }} \times(F K J K)$ 
Weight / Age $(\mathrm{W} / \mathrm{A})=\frac{B B}{\text { umurternak }} \times(F K J K)$

Keterangan :

FKJK = faktor koreksi jenis kelamin

FKUI $=$ faktor koreksi umur induk

$\mathrm{BL}=$ berat lahir

$\mathrm{BS}=$ berat sapih

$\mathrm{BY}=$ berat yearling atau setahuna

$\mathrm{BA}=$ berat akhir

$\mathrm{BL}_{\mathrm{T}}=$ berat lahir terkoreksi

$\mathrm{BS}_{\mathrm{T}}=$ berat sapih terkoreksi ke umur 205 hari

$\mathrm{BY}_{\mathrm{T}}=$ berat yearling atau setahunan terkoreksi ke umur 365 hari

$\mathrm{BA}_{\mathrm{T}}=$ berat akhir terkoreksi ke umur 550 hari

\section{Analisis Data}

Estimasi nilai heritabilitas diestimasi menggunakan metode korelasi saudara tiri sebapak (paternal halfsib correlation). Pemisahan komponen ragam untuk menduga heritabilitas dilakukan dengan analisis ragam menggunakan Rancangan Acak Lengkap pola searah (Completely Randomized Design OneWay Classification) dengan model menurut Becker (1992) dan Hardjosubroto (1994) sebagai berikut:

$\mathrm{Y}_{\mathrm{ik}}=\mu+\sigma_{\mathrm{i}}+\mathrm{e}_{\mathrm{ik}}$

Keterangan:

$\mathrm{Y}_{\mathrm{ik}}=$ pengamatan pada individu ke-k pada pejantan ke-i

$\mu \quad=$ rata-rata populasi

$\sigma_{\mathrm{i}} \quad=$ efek pejantan ke-i

$\mathrm{e}_{\mathrm{ik}} \quad=$ penyimpangan efek lingkungan dan genetik yang tidak terkontrol dari setiap individu

Estimasi heritabilitas $\left(\mathrm{h}^{2}\right)=\frac{4 \sigma_{S}^{2}}{\sigma_{S}^{2}+\sigma_{W}^{2}}$

Standard error $(\mathrm{SE})$ heritabilitas $\left(\mathrm{h}^{2}\right)=$

$4 \sqrt{\frac{2(1-t)^{2}[1+(k-1)(t)]^{2}}{k(k-1)(S-1)}} \quad \mathrm{t}=\frac{\sigma_{S}^{2}}{\sigma_{S}^{2}+\sigma_{W}^{2}}$

$\mathrm{k}=\frac{1}{S-1}\left(N-\frac{\sum n_{i}^{2}}{N}\right)$
Korelasi genetik $\left(\mathrm{r}_{\mathrm{G}}\right)=\frac{\mathrm{côv}_{\mathrm{S}}}{\sqrt{\hat{\sigma}_{\mathrm{S}(\mathrm{X})}^{2} \hat{\sigma}_{\mathrm{S}(\mathrm{Y})}^{2}}}$

Standard error (SE) korelasi genetik = $\sqrt{\operatorname{var}\left(\hat{r}_{G}\right)}$

Keterangan :

$\hat{\sigma}_{S}^{2} \quad=$ ragam pejantan

$\hat{\sigma}_{W}^{2} \quad=$ ragam keturunan dalam pejantan

$\operatorname{cov}_{S}=$ komponen peragam sifat-sifat yang berhubungan dengan pejantan

$\operatorname{cov}_{W}=$ komponen peragam sifat-sifat yang berhubungan dengan keturunan

$\mathrm{S} \quad=$ jumlah pejantan

$\mathrm{N}=$ jumlah anak keseluruhan

$\mathrm{n}_{\mathrm{i}} \quad=$ jumlah anak tiap pejantan

$\mathrm{t}=$ korelasi dalam kelas sebapak

$\mathrm{k}=$ koefisien jumlah anak tiap pejantan

\section{HASIL DAN PEMBAHASAN}

\section{Heritabilitas}

Komponen ragam dan peragam dari hasil estimasi heritabilitas dan korelasi genetik ditampilkan pada Tabel 1. Komponen ragam dan peragam yang diperoleh selanjutnya digunakan untuk mengestimasi nilai heritabilitas dan korelasi genetik. Estimasi nilai heritabilitas sifat pertumbuhan sapi Aceh dan beberapa sapi potong di Indonesia dengan metode korelasi saudara tiri sebapak (paternal halfsib correlation) disajikan pada Tabel 1. Nilai heritabilitas $\mathrm{BL}_{\mathrm{T}}$ yang diperoleh termasuk handal karena memiliki nilai SE yang lebih rendah dari nilai heritabilitas. Tingginya nilai SE pada penelitian ini disebabkan karena jumlah sampel (anak) dan pejantan (sire) yang diestimasi sedikit dan adanya variasi fenotip antar individu yang besar. Diperlukan jumlah sampel minimal 500 sampel agar nilai heritabilitas yang diperoleh handal (Warwick et al.,1990).

Nilai heritabilitas pada penelitian ini dihitung berdasarkan asumsi sapi-sapi yang diestimasi tersebut mendapat pakan yang sama dan berada pada lingkungan yang sama, sehingga mutu genetik ternak dapat diukur. Nilai heritabilitas BL sebesar 0,15 menunjuk- 
Tabel 1. Komponen ragam $\left(\sigma^{2}\right)$ dan estimasi heritabilitas $\left(\mathrm{h}^{2}\right)$ pada sifat pertumbuhan sapi Aceh di BPTU-HPT sapi Aceh Indrapuri

\begin{tabular}{lccccccc}
\hline \hline \multicolumn{1}{c}{ Komponen } & \multicolumn{7}{c}{ Sifat pertumbuhan } \\
\cline { 2 - 8 } & $\mathrm{BL}$ & $\mathrm{BS}$ & $\mathrm{BY}$ & $\mathrm{BA}$ & $\mathrm{PBBH}$ pra & PBBH psc & W/A \\
\hline$\Sigma$ Pejantan (sire) & 9 & 4 & 4 & 4 & 4 & 4 & 4 \\
$\Sigma$ Anak (progeny) & 171 & 48 & 48 & 48 & 52 & 52 & 52 \\
Rata-rata (means) & $14,54 \pm 1,01$ & $46,37 \pm 15,90$ & $71,98 \pm 6,84$ & $99,52 \pm 10,40$ & $0,16 \pm 0,02$ & $0,14 \pm 0,01$ & $0,11 \pm 0,009$ \\
FKJK betina & 1,02 & 1,03 & 1,05 & 1,06 & 1,07 & 1,07 & 1,04 \\
$\sigma_{S}^{2}$ & 0,97 & 12,92 & 38,28 & 93,21 & 0,0003 & 0,0003 & 0,00008 \\
$\sigma_{W}^{2}$ & 3,50 & 93,98 & 274,18 & 575,67 & 0,002 & 0,001 & 0,001 \\
Heritabilitas $\left(\mathrm{h}^{2}\right)$ & $0,15 \pm 0,13$ & $0,48 \pm 0,58$ & $0,49 \pm 0,58$ & $0,56 \pm 0,69$ & $0,53 \pm 0,58$ & $0,64 \pm 0,64$ & $0,42 \pm 0,52$ \\
\hline
\end{tabular}

Keterangan: $\mathrm{BL}=$ berat lahir terkoreksi; $\mathrm{BS}=$ berat sapih terkoreksi 205 hari; $\mathrm{BY}=$ berat setahunan (yearling) terkoreksi 365 hari; BA = berat akhir terkoreksi 550 hari; $\mathrm{PBBH}$ pra = pertambahan berat badan harian prasapih; $\mathrm{PBBH}$ psc $=$ pertambahan berat badan harian pascasapih; $\mathrm{W} / \mathrm{A}=$ Weight/Age

kan bahwa keragaman BL pada populasi $15 \%$ dipengaruhi oleh faktor ragam genetik dari tetuanya. Nilai heritabilitas BL yang diperoleh pada penelitian termasuk handal dan termasuk kategori sedang $\left(0,10 \leq \mathrm{h}^{2} \leq 0,30\right)$ sama seperti pada sapi Golpayeganian $(0,23)$, Charolais $(0,26)$, Santa Getrudis $(0,16)$ dan Zebu cattle $(0,28)$ dan N'Dama cattle $(0,10 \pm 0,05)$ dan Nigerian cattle sebesar

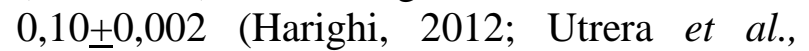
2010; Please et al., 2002; Albuqurque, 2001; Abdullah dan Olutogun, 2006; Sheshu et al., 2008). Sapi Simmental memiliki nilai heritabilitas BL sebesar $0,11 \pm 0,09$ dan pada

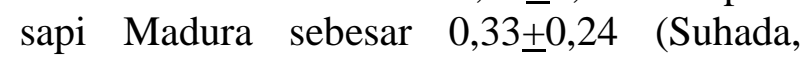
2008; Karnaen, 2004). Sapi Bali memiliki nilai heritabiltas BL sebesar $0,85 \pm 0,44$

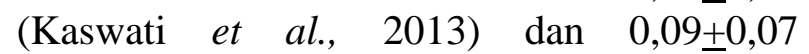
(Gunawan dan Jakaria, 2011). Nilai heritabilitas BL yang tinggi juga dilaporkan pada sapi Brahman $(0,33)$ dan Japanese Black sebesar 0,48 (Albuqurque, 2001; Aziz et al., 2005). Nilai heritabilitas dikatakan rendah jika kurang dari 0,10 ; sedang jika nilainya antara 0,10 sampai 0,30 dan tinggi jika nilainya lebih dari 0,30 (Hardjosubroto, 1994). Hasil yang berbeda dilaporkan pada sapi Red Chittagong yang memiliki nilai heritabilitas BL sebesar 0,49 (Rabeya et al., 2009) dan pada sapi Limmousine sebesar 0,09 termasuk kategori rendah (Niekerk, 2006).

Nilai heritabilitas BS pada sapi Brahman cross $(0,37 \pm 0,09)$, Ongole $(0,27 \pm 0,10)$, Simmental $(0,39 \pm 0,16)$ dan Madura $(0,87$ $\pm 0,45)$. Nilai heritabilitas BY pada sapi
Brahman cross $(0,44 \pm 0,14)$, Ongole $(0,39$ $\pm 0,21)$, Simmental $(0,43 \pm 0,19)$ dan Madura $(0,27 \pm 0,29)$. Nilai heritabilitas PBBH pascasapih pada sapi Brahman cross $(0,41 \pm 0,16)$, Ongole $(0,27 \pm 0,20)$, Simmental $(0,46 \pm 0,20)$ dan Madura sebesar 0,23 $\pm 0,28$ (Duma, 1997; Suhada, 2008; Karnaen, 2004). Nilai heritabilitas BS, BY dan PBBH pascasapih sapi Bali pada tahun 2002 pernah dihitung dengan metode Best Linear Unbiased Predicted (BLUP) multivariate animal model masingmasing sebesar $0,23 \pm 0,02 ; 0,38 \pm 0,03$ dan 0,27 $\pm 0,02$ (Sukmasari et al., 2002). Gunawan dan Jakaria (2011) melaporkan bahwa dengan metode analisis yang sama dengan penelitian ini nilai heritabilitas BS dan BY masingmasing sebesar $0,33 \pm 0,09$ dan $0,43 \pm 0,10$ sedangkan pada tahun 2013 masing-masing sebesar $0,51 \pm 0,32$ dan $0,54 \pm 0,32$ (Kaswati et al., 2013).

Berdasarkan pada hasil penelitian terdahulu tersebut, terlihat bahwa sapi Madura memiliki nilai heritabilitas $\mathrm{BY}$ dan $\mathrm{PBBH}$ pascasapih yang tidak handal sama seperti sapi Aceh pada penelitian ini. Perbedaan nilai heritabilitas pada beberapa penelitian sebelumnya disebabkan karena heritabilitas bukan merupakan konstanta dan bergantung pada jumlah populasi, waktu estimasi dan bangsa ternak (Falconer dan Mackay, 1996). Nilai heritabilitas sifat pertumbuhan pada penelitian ini sebagian besar termasuk kategori tinggi walaupun kurang handal. Heritabilitas suatu sifat yang menunjukkan kategori yang tinggi menunjukkan tingginya korelasi antara 
genetik dan performans yang terukur dan terlihat dari luar, sehingga seleksi individu efektif dilakukan (Warwick et al., 1990).

Berat lahir pada sapi Aceh memiliki nilai heritabilitas kategori sedang sehingga berat lahir masih dapat digunakan sebagai salah satu kriteria seleksi ternak tetapi harus diikuti dengan seleksi induk berdasarkan lebar pinggul dan tinggi pinggul untuk mengurangi resiko dystochia. Seleksi secara terus menerus pada suatu populasi menyebabkan keragaman genetik semakin kecil sehingga nilai heritabilitas juga akan semakin kecil. Sebagai contoh nilai heritabilitas BL pada sapi Bali sebesar $0,09 \pm 0,07$ menunjukkan bahwa sifat BL pada sapi Bali memiliki angka pewarisan yang kecil sehingga kurang seleksi pada sifat tersebut tidak memberikan respon terhadap seleksi yang baik.

\section{Korelasi Genetik}

Korelasi genetik pada sifat pertumbuhan pada penelitian dapat dilihat pada Tabel 2 . Nilai korelasi genetik yang handal ditunjukkan pada BL dengan PBBH prasapih dan $\mathrm{BL}_{\mathrm{T}}$ dengan $\mathrm{PBBH}$ pascasapih. Sapi yang memiliki BL yang tinggi akan lebih cepat tumbuh dibandingkan sapi dengan BL rendah. Sapi yang memiliki BL tinggi juga memiliki daya tahan yang lebih baik (Hardjosubroto, 1994). Seleksi pada BL juga harus diikuti dengan seleksi induk, terutama pada ukuran tubuh antara lain lebar pinggul dan tinggi pinggul untuk mengurangi resiko terjadinya dystochia (Supiyono, 1998). Dengan melakukan seleksi pada BL secara tidak langsung induk juga ikut terseleksi. Induk yang rata-rata keturunannya BL yang tinggi berarti induk tersebut memiliki produktivitas yang baik (Kurnianto, 2009).

Nilai korelasi genetik PBBH prasapih dengan $\mathrm{PBBH}$ pascasapih menunjukkan nilai yang positif tinggi dan termasuk handal. Sifat pertumbuhan prasapih yang tinggi dapat digunakan sebagai kriteria seleksi ternak untuk memperoleh sifat pertumbuhan pascasapih yang tinggi. Nilai korelasi genetik PBBH pascasapih dengan W/A juga memiliki nilai yang positif tinggi dan handal sama seperti korelasi antara $\mathrm{BA}_{\mathrm{T}}$ dengan W/A Tingginya nilai SE pada korelasi genetik juga disebabkan karena jumlah data (pengamatan) dan jumlah pejantan yang digunakan untuk estimasi sedikit sehingga akan mempengaruhi keragaman antar pejantan dan keragaman antar individu.

Nilai korelasi genetik BL dengan PBBH prasapih pada sapi Madura 0,38 dan termasuk positif tinggi (Karnaen, 2004) sama seperti pada penelitian ini. Nilai korelasi genetik antara BA dengan BS, BY, PBBH prasapih dan $\mathrm{PBBH}$ pascasapih pada penelitian ini termasuk kategori tinggi tetapi tidak handal sama seperti pada sapi Nellore yang memiliki nilai korelasi genetik pada sifat BA dengan BS $(0,63)$, BY $(0,71)$, PBBH prasapih $(0,47)$ dan PBBH pascasapih sebesar 0,48 (Regatieri et al., 2012). Nilai korelasi genetik antara BL dengan BS, BY dan BA pada sapi Golpayeganian berturut-turut sebesar 0,$29 ; 0,26$ dan 0,10 (kategori rendah) sedangkan pada sapi Limousine masing-masing sebesar 0,41;0,37 dan 0,33 termasuk kategori sedang (Harighi, 2007; Niekerk, 2006). Nilai korelasi genetik $\mathrm{BL}_{\mathrm{T}}$ dengan $\mathrm{BS}$ dan $\mathrm{BY}$ pada penelitian ini termasuk kategori tinggi tetapi tidak handal. Sifat $\mathrm{BY}_{\mathrm{T}}$ dengan $\mathrm{PBBH}$ pascasapih termasuk kategori tinggi tetapi tidak handal $(0,51 \pm 0,95)$ sedangkan pada sapi Bhagnari x Drugsmaster nilainya diluar kisaran normal yaitu 1,59 (Khan et al,. 1998).

Berdasarkan Tabel 2 diketahui bahwa nilai korelasi genetik antara dua sifat yang nilai heritabilitasnya tidak handal belum tentu nilainya juga tidak handal, karena bergantung pada besarnya nilai komponen ragam $\left(\sigma^{2}\right)$ dan peragam $\left(\operatorname{cov}^{2}\right)$ yang menyusunnya.

\section{KESIMPULAN}

Heritabilitas BL sapi Aceh pada penelitian ini memiliki tingkat keterandalan yang baik karena memiliki nilai SE yang rendah. Berat lahir pada sapi Aceh juga memiliki nilai korelasi genetik yang positif tinggi dan handal terhadap $\mathrm{PBBH}$ prasapih dan $\mathrm{PBBH}$ pascasapih. 
Tabel 2. Komponen peragam (côv) dan dan estimasi korelasi genetik $\left(r_{G}\right)$ sifat pertumbuhan pada sapi Aceh di BPTU-HPT sapi Aceh Indrapuri

\begin{tabular}{|c|c|c|c|c|c|c|}
\hline \multirow[t]{2}{*}{ Peragam X } & \multicolumn{6}{|c|}{ Peragam Y } \\
\hline & BS & BY & BA & PBBH pra & PBBH psc & W/A \\
\hline \multicolumn{7}{|l|}{ BL } \\
\hline$\Sigma$ Sire & 4 & 4 & 4 & 4 & 4 & 4 \\
\hline$\Sigma$ Progeny & 52 & 52 & 52 & 52 & 52 & 52 \\
\hline $\operatorname{cov}_{S}$ & 1,97 & 3,14 & 4,99 & 0,01 & 0,01 & 0,005 \\
\hline $\operatorname{côv}_{W}$ & 0,58 & 0,89 & $-1,10$ & $-0,004$ & 0,002 & 0,004 \\
\hline$r_{G}$ & $0,56 \pm 0,60$ & $0,52 \pm 0,62$ & $0,52 \pm 0,59$ & $0,55 \pm 0,54$ & $0,63 \pm 0,62$ & $0,57 \pm 0,69$ \\
\hline \multicolumn{7}{|l|}{$\mathrm{BS}$} \\
\hline$\Sigma$ Sire & - & 3 & 3 & 3 & 3 & 3 \\
\hline$\Sigma$ Progeny & - & 24 & 24 & 24 & 24 & 32 \\
\hline $\operatorname{côv}_{S}$ & - & 10,24 & 12,94 & 0,03 & 0,03 & 0,02 \\
\hline $\operatorname{cov}_{W}$ & - & 76,62 & 92,52 & 0,21 & 0,20 & 1,21 \\
\hline$r_{G}$ & - & $0,46 \pm 1,00$ & $0,37 \pm 0,58$ & $0,34 \pm 0,81$ & $0,50 \pm 0,96$ & $0,63 \pm 1,91$ \\
\hline \multicolumn{7}{|l|}{ BY } \\
\hline$\Sigma$ Sire & - & - & 3 & 3 & 3 & 3 \\
\hline$\Sigma$ Progeny & - & - & 24 & 24 & 24 & 39 \\
\hline $\operatorname{côv}_{S}$ & - & - & 23,37 & 0,04 & 0,05 & 0,03 \\
\hline $\operatorname{côv}_{W}$ & - & - & 160,69 & 0,36 & 0,35 & 0,10 \\
\hline$r_{G}$ & - & - & $0,39 \pm 1,03$ & $0,39 \pm 0,91$ & $0,51 \pm 0,95$ & $0,55 \pm 0,61$ \\
\hline \multicolumn{7}{|l|}{$\mathrm{BA}$} \\
\hline$\Sigma$ Sire & - & - & - & 3 & 3 & 3 \\
\hline$\Sigma$ Progeny & - & - & - & 24 & 24 & 24 \\
\hline $\operatorname{côv}_{S}$ & - & - & - & 0,06 & 0,06 & 0,08 \\
\hline $\operatorname{côv}_{W}$ & - & - & - & 0,44 & 0,28 & 0,28 \\
\hline$r_{G}$ & - & - & - & $0,32 \pm 1,10$ & $0,39 \pm 1,04$ & $0,94 \pm 0,69$ \\
\hline \multicolumn{7}{|l|}{ PBBH pra } \\
\hline$\Sigma$ Sire & - & - & - & - & 4 & 4 \\
\hline$\Sigma$ Progeny & - & - & - & - & 52 & 52 \\
\hline côv $_{S}$ & - & - & - & - & 0,0002 & 0,00004 \\
\hline $\operatorname{côv}_{W}$ & - & - & - & - & 0,001 & 0,001 \\
\hline$r_{G}$ & - & - & - & - & $0,71 \pm 0,33$ & $0,23 \pm 0,64$ \\
\hline \multicolumn{7}{|l|}{ PBBH psc } \\
\hline$\Sigma$ Sire & - & - & - & - & - & 4 \\
\hline$\Sigma$ Progeny & - & - & - & - & - & 52 \\
\hline $\operatorname{côv}_{S}$ & - & - & - & - & - & 0,0001 \\
\hline $\operatorname{côv}_{W}$ & - & - & - & - & - & 0,0007 \\
\hline $\operatorname{côv}_{W}$ & - & - & - & - & - & $0,72 \pm 0,33$ \\
\hline
\end{tabular}

Keterangan: $\mathrm{BL}=$ berat lahir terkoreksi; $\mathrm{BS}=$ berat sapih terkoreksi 205 hari; $\mathrm{BY}=$ berat setahunan (yearling) terkoreksi 365 hari; $\mathrm{BA}=$ berat akhir terkoreksi 550 hari; $\mathrm{PBBH}$ pra = pertambahan berat badan harian prasapih; $\mathrm{PBBH}$ psc $=$ pertambahan berat badan harian pascasapih; $\mathrm{W} / \mathrm{A}=$ Weight/Age. . 


\section{UCAPAN TERIMA KASIH}

Penulis menyampaikan terima kasih kepada seluruh staf dan karyawan di BPTUHPT Sapi Aceh Indrapuri atas bantuan dan dukungannya sehingga penelitian ini dapat diselesaikan dengan baik. Penulis juga menyampaikan terima kasih kepada Bapak Hendra Saumar, S.Pt. atas partisipasinya dalam pengumpulan data recording sapi Aceh.

\section{DAFTAR PUSTAKA}

Abdullah, A. R. and O. Olutogun. 2006. Estimation of genetic and phenotypic parameters for preweaning growth traits of N'Dama (Bos taurus) calves in the humid tropics of Nigeria. Livest. Res.Rur.Develop. http//www.cipav.org. [16 Februari 2014].

Albuquerque, G. L. 2001. Estimates of direct and maternal genetic effect for weight from birth to 600 days of age in Nellore cattle. J. Anim. Breed. Genet. 118: 83-92.

Aziz, M. A., S. Nishida, K. Suzuki and A. Nishada. 2005. Estimation of direct and maternal and permanent environmental effect for wight from birth to 356 days of age in a herd of Japanese Black cattle using random regression, J. Anim.Sci. 83: 519-530.

Becker, W. A. 1992. Manual of Quantitative Genetics. $4^{\text {th }}$ ed. Washington State University, USA.

Blakley, J dan H. Bade. 1992. Ilmu Peternakan. Gajah Mada University Press. Yogyakarta.

Duma, Y. 1997. Estimasi beberapa parameter genetik pada sapi Brahman Cross dan Ongole di ladang ternak Bila River Ranch. Thesis. Program Pascasarjana, Universitas Gadjah Mada, Yogyakarta.

Falconer, D. S. and T. F. Mackay. 1996. Introduction to quantitative genetics. $4^{\text {th }}$ Edition. Department of Genetics. North Canada State University.
Gunawan, A. and Jakaria. 2011. Genetic and non genetic effect on birth, weaning and yearling weight in Bali cattle. Media Peternakan. 34(2): 93-98.

Hardjosubroto, W. 1994. Aplikasi Pemuliabiakan Ternak di Lapangan. Gramedia Widiasarana Indonesia, Jakarta.

Harighi, M. F. 2007. Estimated of genetic parameters of growth Golpayeganian calves. Pakistan. J. Biol. Sci. 5: 112115.

Jamaliah. 2010. Pelestarian plasma nutfah sapi Aceh. Balai Pembibitan Ternak Unggul sapi Aceh (BPTU) Indrapuri, Aceh.

Karnaen. 2004. Pendugaan parameter genetik, korelasi genetik dan fenotipik pada sapi Madura. J. Indonesian. Trop. Anim. Agric. 25(2):12-24.

Kaswati, N. Sumadi dan Ngadiono. 2013. Estimasi nilai heritabilitas berat lahir, sapih dan umur satu tahun pada sapi Bali di Balai Pembibitan Ternak Unggul Sapi Bali. Buletin Peternakan. 37(2): 7478.

Khan, M.S., M. Younas and M.A. Khan. 1998. Genetic and phenotypic (co)variance for growth traits in Baghnari $\mathrm{x}$ Droughtmaster calves. Pakistan. J. Biol. Sci. 1: 202- 204.

Kurnianto, E. 2009. Pemuliaan Ternak. Graha Ilmu, Jakarta.

Niekerk, M. and F.W.C. Neser. 2006. Genetic parameters for growth traits in South African Limmousine cattle. S. Afr. J. Anim. Sci. 36: 6-9.

Please, D., O.Verde, H. Fossi, R. Romero, R. Hoogestejin, P. Bastidas and J. Bastardo. 2002. (Co)variance components, genetics parameter and anual trends for calf weights in a pedigree Brahman herd under selection for 3 decades. J. Anim. Breed. Genet. 119: 141-153.

Rabeya, T., A. K. F. H. Bhuiyan, M. A. Habib and M.S. Hossain. 2009. Phenotypic and 
genetic parameters for growth traits in Red Chittagong cattle. J. Bangladesh Agri. Univ. 7: 265-271.

Regatieri, I. C., A. A. Boligon, F. Baldi and L.G. Alburquerque. 2012. Genetic correlations between mature cow weight and productive and reproductive traits in Nellore cattle. Genetics and Molecular Research. 11: 2979-2986.

Riady, M.. 2007. Petunjuk teknis uji performans sapi potong nasional. Direktorat Jendral Peternakan. Departemen Pertanian. Jakarta.

Sheshu, D. M., O. O. Oni, S. A. S. Olorunju, and I. A. Adeyinka. 2008. Genetic and phenotypic parameters for body weight of Sokoto Gudali (Bokoloji) cattle Int. Jor. P.App. Scs. 2: 64-67.

Suhada, H. 2008. Estimasi parameter genetik sifat produksi sapi Simmental di Balai Pembibitan Ternak Unggul Sapi Potong Padang Mengatas Sumatera Barat. Thesis. Program Pascasarjana,
Universitas Gadjah Mada, Yogyakarta.

Sukmasari, A. H., R. N. Ronny dan T. Chalid. 2002. Pendugaan nilai pemuliaan dan kecenderungan genetik sapi Bali di proyek pembibitan dan pengembangan sapi Bali. J. Hayati. 9(4):109-113

Supiyono. 1998. Ilmu Tilik Ternak. Fakultas Peternakan, Universitas Gadjah Mada, Yogyakarta.

Umartha, B. A. 2005. Mengenal karakteristik sapi Aceh. Balai Pembibitan Ternak Unggul (BPTU) Indrapuri, Banda Aceh.

Utrera, A. R., V. E. V. Murillo, G. M. Velazquez and M. M. Bermudez. 2010. Estimation of genetic effects for growth traits of Mexican Charolais cattle using alternative models. Livest. Prod. Sci. 60: 203-208.

Warwick, E. J., J. W. Astuti, W. Hardjosubroto. 1990. Pemuliaan Ternak. Gadjah University Press, Yogyakarta. 